\title{
PRÁTICAS DE LETRAMENTOS LITERÁRIOS DE REEXISTÊNCIA NA OFICINA DE SARAU DO COLETIVOZ SARAU DE PERIFERIA
}

\author{
REEXISTENCE LITERARY LITERACY PRACTICES IN THE SOIREE WORKSHOP \\ OF COLETIVOZ SARAU DE PERIFERIA
}

\author{
Lucia Tennina* \\ Marta Passos Pinheiro** \\ Luiz Eduardo Rodrigues de Almeida Souza ${ }^{* * *}$
}

\begin{abstract}
RESUMO
Este artigo busca caracterizar as práticas de letramentos literários realizadas no primeiro dia da oficina de sarau ministrada pelo Coletivoz Sarau de Periferia, em junho de 2017, no Centro Cultural Urucuia, localizado na região do Barreiro, em Belo Horizonte. Esse coletivo, fundado pelo poeta Rogério Coelho, nasceu em 2008 inspirado no Sarau da Cooperifa de São Paulo, vinculando-se, assim, ao movimento e à cena da literatura marginal da periferia da capital paulista. A oficina faz parte do projeto Coletivoz Oficina de Saraus, voltado para alunos da rede pública de ensino, com o objetivo de incentivar a leitura literária e a escrita criativa por meio da performance poética que circula nos saraus periféricos de literatura marginal contemporânea. Por meio de observação participante e gravação de áudio, foram analisadas algumas ações, discussões e falas dos oficineiros e dos estudantes. Como fundamentação teórica, foram utilizados os conceitos: de práticas de letramento, de Brian Street (2014), de letramento literário, de Graça Paulino e Rildo Cosson (2009), e de letramentos de reexistência, de Ana Lúcia Silva Souza (2011). Observamos que os eventos e as práticas de letramento da oficina são marcados pela interação das fórmulas rituais dos saraus das periferias com as da escola, incorporadas nos participantes e recriadas nesse encontro fora dos bares e da instituição escolar. Nessa interação, cria-se a possibilidade de a escola revisitar suas práticas de letramento, ampliando seu repertório, revendo suas metodologias e também contribuindo com práticas de letramentos literários de reexistências.
\end{abstract}

Palavras-chave: letramentos literários; literatura marginal da periferia; oficina de sarau; letramentos de reexistência.

\section{ABSTRACT}

This paper aims the characterization of the literary literacy practices performed on the first day of the soiree workshop lead by Coletivoz Sarau de Periferia, in June 2017, at the Urucuia Cultural Center. This Collective, founded by the poet Rogerio Coelho, was born in 2008, inspired by the Cooperifa Soiree of São Paulo, thus linking itself to the movement and scene of marginal literature of São Paulo's periphery. The workshop is part of the Project Coletivoz Soirees, directed to public school students, with the aim of encouraging literary reading and creative writing through the poetic performance that circulates at the perpheric soirées of contemporary marginal literature. Through participant observation and audio recording some actions, discussions and lines of the students and oficineiros were analyzed. The concepts of literacy practices (STREET, 2014), literary literacy (PAULINO e COSSON, 2009) and reexistence literacy (SOUZA, 2011) constitute the theorerical basis of the discussion. It was observed that the events and the workshop literacy practices are characterized by the interaction of the ritual formula of the soirees in the peripheries with the ones of the schools, incorporated in the participants and recreated in these meetings outside the bars and the educational institutions. In this interaction, it is created for the school a possibility to revisit its literacy pratices, broadening its repertoire, reviewing its methodology and in addition it contributes to its literary literacy practices of reexistence.

Keywords: literary literacies; marginal literature from the periphery; soiree workshop; Reexistence literacies.

\section{INTRODUÇÃO}

O Coletivoz Sarau de Periferia, grupo pioneiro da cena marginal mineira, realizou, durante os anos de 2016 e 2017, oficinas de sarau para alunos e professores de escolas estaduais e municipais da região do Barreiro, em Belo Horizonte. Esses encontros fizeram parte do projeto Oficina de Saraus, aprovado pelo edital Descentra Cultura da prefeitura municipal de Belo Horizonte ${ }^{1}$. As oficinas tiveram a duração de nove horas cada uma, distribuídas

* Universidade de Buenos Aires, Buenos Aires, Argentina. luciatennina@gmail.com

Orcid: https://orcid.org/0000-0002-5652-6234

** Centro Federal de Educação Tecnológica de Minas Gerais (CEFET-MG), Belo Horizonte, MG, Brasil. martapassaro@gmail.com Orcid: https://orcid.org/0000-0001-9245-0823

***Doutorando do Centro Federal de Educação Tecnológica de Minas Gerais (CEFET-MG), Belo Horizonte, MG, Brasil. luizeduardordealmeidasouza@gmail.com

Orcid: https://orcid.org/0000-0001-5157-9372

1. O projeto foi contemplado pelo edital Descentra Cultura 2015, da Fundação Municipal de Cultura, que objetiva a descentralização do orçamento das políticas culturais em Belo Horizonte. Aqui pontuamos a importância desse edital para diminuir a predominância dos recursos públicos na zona centro-sul da cidade, que historicamente é beneficiada pela maior parcela do orçamento destinado às áreas culturais. 
em três horas diárias, e foram realizadas nos centros culturais Urucuia, Vila Santa Rita e Lindeia Regina. A última aconteceu nos dias 07, 08 e 09 de junho de 2017, no Centro Cultural Urucuia, e dela participaram três poetas e rappers do Coletivoz como oficineiros (Eduardo DW, Beluca e Belinha) e os estudantes do $3^{\circ}$ ano do Ensino Médio acompanhados por uma professora de uma das escolas municipais do bairro Cardoso. Este artigo busca caracterizar as práticas de letramentos literários presentes no primeiro dia dessa última oficina. Interessa-nos investigar aproximações, diálogos e afastamentos entre práticas não-escolares, próprias dos saraus, e práticas escolares.

Para este trabalho, nos detivemos na análise de algumas ações e interações dos estudantes e oficineiros registradas por meio de observação participante e gravação de áudio. Como fundamentação teórica, utilizamos os conceitos de: práticas de letramento, de Brian Street (2014), letramento literário, de Graça Paulino e Rildo Cosson (2009), e letramentos de reexistência, de Ana Lúcia Silva Souza (2011). Para a discussão sobre literatura marginal das periferias, dialogamos com Érica Peçanha do Nascimento (2006 e 2011), Alejandro Reyes (2013), Tennina (2017) e Rogério Meira Coelho (2017).

Em um primeiro momento, contextualizamos o movimento dos saraus das periferias e da literatura marginal vinculado com a cena de Belo Horizonte, em seguida apresentamos uma breve discussão sobre as concepções de letramento que fundamentam nosso trabalho e, por fim, apresentamos a análise das práticas de letramentos literários realizadas no primeiro dia da oficina.

\section{SARAUS DAS PERIFERIAS}

Em 2001, com a criação do Sarau da Cooperifa no bar do Zé Batidão, localizado no bairro de Chácara Santana, uma das periferias da zona sul da cidade de São Paulo, começou a nascer um circuito literário independente do centro hegemônico de produção da cultura na cidade, conformado por vários saraus que se espalhavam por diferentes bairros da capital paulista. Como é explicado por Tennina:

A implantação do nome sarau, sua regularidade e a distinção de certas fórmulas rituais (como o tempo de declamação, o silêncio, o aplauso etc.) em função de certa ideia de periferia foram os elementos-guia que o Sarau da Cooperifa inspirou e permitiram que se distinguisse e dispersasse essa prática em outros bairros e bares (2017, p. 51).

Essa replicação pouco a pouco alcançou uma dimensão ainda maior e começaram a ser criados saraus em favelas e bairros periféricos de outras regiões do país. Os laços estéticos e ideológicos entre os saraus permitiram identificar esse circuito também como uma cena (NASCIMENTO, 2006), mas sobretudo como um movimento literário (TENNINA, 2017), com o foco na inscrição de corpos e vozes historicamente apagados e silenciados no campo literário brasileiro. Os saraus começaram a realizar iniciativas além dos muros dos bares, como ações educativas, de economia solidária, de protesto etc, sendo também identificados como um movimento social (REYES, 2013).

Paralelamente ao movimento dos saraus das periferias nos centros urbanos brasileiros, diversos textos de escritores das periferias começaram, também em 2001, a ser publicados em formato impresso e a adquirir uma visibilidade maior. O ponto de inflexão foi a publicação da edição especial da Revista Caros Amigos intitulada "Literatura Marginal. A Cultura da periferia", organizada pelo escritor Ferréz, que contou com mais dois números (chamados "atos") nos anos 2002 e 2004. Cada um desses números abria com um Manifesto dando forma e consistência à ideia de Literatura Marginal, não somente em termos estéticos e territoriais, mas também a partir de uma genealogia de autores (João Antônio, Carolina Maria de Jesus, Plínio Marcos) em função de fortalecer esse conceito em uma perspectiva histórica.

Um ano antes das antologias da Caros Amigos, Ferréz publicou o seu primeiro romance, Capão Pecado, pela editora Labortexto, ganhando um grande destaque dentro da literatura brasileira contemporânea. Nessa mesma época, a editora Global, sob organização de Antonio Eleilson Leite, coordenador da ONG Ação Educativa (um espaço localizado no centro de São Paulo que congregava a cena cultural das periferias), criou a Coleção Literatura Periférica. Essa coleção publicou no total 10 títulos da chamada "primeira geração" (NASCIMENTO, 2011) de autores das periferias, isto é, aqueles que produziam livros autorais, livretos artesanais ou zines quando ainda não existia o circuito dos saraus.

Essas premissas contextuais de marcos sociais, geracionais e editoriais serviram de inspiração e impulso para o processo de fundação do primeiro sarau periférico na cidade de Belo Horizonte que autoidentifica a sua 
produção como literatura marginal: o Coletivoz Sarau de Periferia, que iniciou suas ações no dia 10 de setembro de 2008 (COELHO, 2017). Assim como o Cooperifa que o inspirou, o Coletivoz começou em um bar, o bar do seu Zé Herculano, localizado no bairro Independência, na região do Barreiro, extremo oeste de Belo Horizonte. Zé Herculano aceitou a proposta de seu filho, Rogério Coelho, um dos fundadores do Coletivoz, de acolher em seu espaço o grupo de poetas mineiros encantados com as experiências dos movimentos de saraus de literatura marginal em São Paulo. Como é informado por Rogério Coelho, o sarau foi formado a partir de "um desejo de se criar na capital mineira um evento contínuo de mesmo porte, além de estabelecer um ponto de referência cultural periférica na região do Barreiro, a maior da cidade."(COELHO, 2017, p.36-37). Esse coletivo poético é formado por vários poetas e rappers de bairros periféricos, entre eles estão Eduardo DW, Fellipe Beluca e Isabela Alves (Belinha), que ministraram a Oficina de Sarau analisada neste artigo.

O Coletivoz, depois de oito anos de jornada cultural nas periferias da cidade, começou a atuar também em outras quebradas da paisagem urbana, bem como ocupou espaços culturais, mesmo que pontualmente, do centro da cidade, os quais se associam às artes cênicas, aos movimentos da cultura hip-hop, às redes de lutas por direitos humanos (reforma urbana, ONG etc.). Neste artigo destacamos o trabalho desse coletivo junto a escolas públicas por meio do projeto Oficina de Saraus. Buscam-se observar relações entre o "espaço da rua" e o "espaço da escola", entre práticas escolares e não-escolares de letramento.

\section{LETRAMENTOS LITERÁRIOS DE REEXISTÊNCIAS}

Para a análise proposta neste artigo, letramento é concebido em sua dimensão social (STREET, 2014), ou seja, deve ser compreendido de forma contextualizada, nas diversas práticas de oralidade, leitura e escrita da sociedade. Essa concepção, que corresponde ao modelo ideológico proposto pelos New Literacy Studies, tem como importante representante Brian Street, e se contrapõe à concepção nomeada por ele de modelo autônomo de letramento, pautada nas habilidades adquiridas pelo indivíduo. Segundo o autor, as pessoas que aderem ao modelo ideológico,

se concentram em práticas sociais específicas de leitura e escrita. Reconhecem a natureza ideológica e, portanto, culturalmente incrustadas dessas práticas. O modelo ressalta a importância do processo de socialização na construção do significado do letramento para os participantes e, portanto, se preocupa com as instituições sociais gerais por meio das quais esse processo se dá, e não somente com as instituições "pedagógicas". Ele distingue as alegadas consequências do letramento de sua real importância para grupos sociais.

[...] Concentra-se na sobreposição e na interação das modalidades oral e escrita, em vez de enfatizar uma "grande divisão". (STREET, 2014, p. 44).

Para a descrição dos letramentos, nessa perspectiva, Street utiliza o conceito de práticas de letramento, descrito como um desenvolvimento do conceito de eventos de letramento, de Heath (STREET, 2014, p. 18), que não só incorporam estes últimos, "como ocasiões empíricas às quais o letramento é essencial, mas também modelos populares desses eventos e as preconcepções ideológicas que os sustentam." (STREET, 2014, p. 18). Nesse sentido, existe uma diferença entre eventos de letramentos e práticas de letramento. Como definem Street e Castanheira:

A expressão eventos de letramento refere-se aos elementos mais observáveis das atividades que envolvem a leitura e a escrita, enquanto o conceito de práticas de letramento distancia-se do contexto imediato em que os eventos ocorrem, para situá-los e interpretá-los em contextos institucionais e culturais a partir dos quais os participantes atribuem significados à escrita e à leitura, e aos eventos de que participam. (2014, p. 258-259).

Sendo assim, nos eventos de letramentos, podemos observar determinadas práticas de letramentos, que estão relacionadas a concepções de escrita e leitura de um grupo social.

Dentro da concepção pluralista de letramento, encontra-se também a Pedagogia dos Multiletramentos, proposta em um artigo publicado na revista Harvard Educational Review, em 1996, por dez autores, integrantes do New London Group. Todos eles são educadores que se reuniram na cidade de New London, nos Estados Unidos, em setembro de 1994, para discutir o "estado" da pedagogia do letramento (CAZDEN et al., 1996, p. 62). Nesse artigo, que é concebido como um manifesto pedagógico, dois aspectos da "multiplicidade dos discursos" são destacados (CAZDEN et al. 1996, p. 61): a diversidade cultural e linguística das sociedades, cada vez mais globalizadas (referem-se às sociedades ocidentais das quais fazem parte), e a diversidade de text forms associadas às tecnologias de informação e multimídia. Essa associação tem suscitado uma leitura dos Multiletramentos que prioriza o uso de TDIC (Tecnologias Digitais da Informação e Comunicação). 
A complexidade e a pluralidade do conceito de letramento, na literatura, é proposta no Brasil por Graça Paulino em 1998. Em 2009, ela reformula a definição de letramento literário e apresenta, juntamente com Rildo Cosson, a seguinte reelaboração: "letramento literário como o processo de apropriação da literatura enquanto construção literária de sentidos." (PAULINO, COSSON, 2009, p. 67). Três aspectos são explicitados pelos autores. Letramento literário é um processo e não uma habilidade, ou seja, deve ser tomado como "um estado permanente de transformação." (PAULINO; COSSON, 2009, p. 67). Letramento literário é uma apropriação, devendo, portanto, ser incorporado e transformado pelo sujeito, é "um ato de tornar próprio" (PAULINO, COSSON, 2009, p. 67). Letramento literário é uma "apropriação da literatura" (PAULINO, COSSON, 2009, p. 68), o que também implica não apenas o que será incorporado, mas também "um repertório que proporciona uma forma singular - literária - de construção de sentidos." (PAULINO; COSSON, 2009, p. 68).

Os dois primeiros aspectos explicitados demonstram a filiação do conceito à perspectiva social de letramento, contudo, o terceiro parece se aproximar da perspectiva tecnicista do letramento autônomo, afinal: o que define a "forma literária" de construção de sentidos? Nem todo repertório proporciona esse tipo de construção? É necessário que o leitor tenha/desenvolva habilidades específicas para ler "de forma literária"? Acreditamos que um caminho para resolver esse impasse é considerar o conceito no plural: letramentos literários, marcando a variedade de repertórios literários e de formas de apropriação desses repertórios.

O conceito de letramentos de reexistência cunhado por Ana Lúcia Silva Souza (2011) é fruto de sua pesquisa de doutorado sobre os letramentos na cultura hip-hop, concebida como uma agência de letramento. Souza traz, assim, uma importante contribuição para as pesquisas de letramento, destacando o caráter social e múltiplo das práticas analisadas e propondo pontes entre práticas não-escolares e escolares. Para ela, os letramentos de reexistência mostram-se singulares, pois,

ao capturarem a complexidade social e histórica que envolve as práticas cotidianas de uso da linguagem, contribuem para a desestabilização do que pode ser considerado como discursos já cristalizados em que as práticas validadas sociais de uso da língua são apenas as ensinadas e aprendidas na escola formal. (SOUZA, 2011, p. 36)

As práticas de reexistência são relacionadas à afirmação de identidades, às ações de resistência, de "microrresistências cotidianas ressignificadas na linguagem, na fala, nos gestos, nas roupas..." (SOUZA, 2011, p. 37), que demarcam sua existência, ressignificando-a. Em sua pesquisa, Souza afirma que,

Para os rappers, a educação e a posse da palavra são marcadas pelo esforço de reconhecimento de si, desafiando, de diferentes maneiras e em diferentes formatos, a sujeição oficialmente imposta, ainda materializada no racismo, nos preconceitos e discriminações. (SOUZA, 2011, p. 37).

Podemos observar essa característica nas práticas de letramentos que envolvem a literatura marginal das periferias em seus vários eventos, tanto nas oficinas, quanto nos saraus e slams. A reexistência está presente nas temáticas dessa literatura - de afirmações identitárias, críticas e denúncias sociopolíticas - e em suas linguagens: poema falado, gritado, gesticulado, cantado, dançado e também escrito e editado, às vezes artesanalmente, às vezes autopublicado, ou produzido por pequenas editoras, a maioria independentes.

\section{LETRAMENTOS LITERÁRIOS DE REEXISTÊNCIA NO COLETIVOZ OFICINA DE SARAU}

Como já foi destacado, escolhemos para a análise proposta neste artigo o primeiro dia da Oficina de Sarau realizada no Centro Cultural Urucuia, da qual participaram 18 alunos e uma professora do $3^{\circ}$ ano do Ensino Médio de uma escola estadual do bairro Cardoso, na região do Barreiro. De acordo com o projeto aprovado pela Fundação Municipal de Cultura:

As oficinas de sarau têm o objetivo de propor uma discussão artística tendo em vista a valorização do jovem e a ressignificação da sua cidadania e de seus direitos tendo como base o fazer poético periférico, fazendo com que esse jovem crie repertório crítico, estético e social que o permitirá acessar os bens simbólicos e culturais tendo como base a autonomia. (COELHO, 2015, p.10).

Podemos observar a presença do conceito de letramento como prática social, uma vez que é destacado o "fazer poético" para além da escrita e leitura em si, voltado para uma ação social. O conceito de letramento de reexistência 
também está presente nesse objetivo, que busca o reconhecimento das identidades dos jovens como sujeitos com direitos.

Com esse propósito, os organizadores do projeto abordaram diferentes temáticas em cada encontro, de três horas cada um: no primeiro dia o tema identidade, no segundo, criação artística, e no último dia discutiram o território. Para este trabalho selecionamos as ações do primeiro dia da oficina especificamente porque foi nele que as fórmulas rituais do sarau foram apresentadas e experienciadas pela primeira vez pelos participantes. Descrevemos cenas e diálogos cujos conteúdos são analisados a partir das discussões acadêmicas sobre: literatura marginal das periferias (NASCIMENTO; TENNINA; COELHO), letramentos literários no espaço escolar (PAULINO; COSSON) e letramentos de reexistência (SOUZA). Pretendemos refletir sobre as práticas dos letramentos a partir das propostas pedagógicas e dos textos poéticos apresentados na oficina, no entrelaçamento das experiências do sarau nos espaços do bar/rua e na escola/centro cultural. Os dados utilizados para a análise baseiam-se no registro via gravações de áudios das interações verbais entre os oficineiros e os/as educandos/as e uma professora da turma.

A oficina foi iniciada pelo rapper e poeta Eduardo DW apresentando a proposta de trabalho para os três dias planejados. DW, juntamente com Rogério Coelho, é um dos articuladores e corresponsáveis dos saraus realizados pelo Coletivoz. Com os alunos e uma professora sentados em cadeiras dispostas em círculo no pequeno auditório do Centro Cultural, com o palco principal ao fundo, Eduardo DW começou tomando a palavra, relembrando o objetivo geral do projeto que pretendia "instigar os alunos à prática dos saraus periféricos como ponto de referência artísticocultural em seus respectivos espaços de formação/fruição (escola/rua)" (COELHO, 2015, p.1). Ele convidou os alunos a organizarem, depois da experiência na oficina, um sarau em suas escolas ou em outro espaço de suas comunidades, o que já havia ocorrido com alunos de outras escolas que participaram da oficina do Coletivoz. A oficina funciona, assim, como uma agência de letramento, responsável pela junção entre conhecimento prático, da experiência dos poetas nos saraus, e conhecimento teórico, desenvolvido por eles a partir da reflexão sobre suas práticas. A oficina é o espaço de compartilhamento dessas experiências. Entendemos, nesse caso, como "agência de letramento" não apenas ambientes onde ocorrem eventos de letramento, mas também ambientes que os propiciam e desenvolvem.

Logo após, DW e os outros dois oficineiros do Coletivoz presentes, os poetas e rappers Fellipe Beluca e Belinha (Isabela Costa), se apresentaram e contaram a história dos saraus marginais na cidade, partindo do pioneiro Sarau Cooperifa de São Paulo. Foram mencionados os seguintes saraus de Belo Horizonte e região metropolitana: Coletivoz Sarau de Periferia, Sarau Vira-Latas, Sarau Cabeçativa e Batalha da Pista. Para essa retrospectiva histórica, Belinha fotografou o mapa do "Atlas dos Saraus da Região Metropolitana de Belo Horizonte" construído pela poeta e pesquisadora Camila Félix em 2018.

Em seguida, DW reforçou a importância de saber a história dos saraus das periferias e suas ações atuais na cidade para a compreensão de "nossas identidades" como "cidadãos atuantes na sociedade". O poeta-oficineiro expôs um conceito sobre identidade para além do nome, RG, família, ou do que o "senso comum" enxerga nesse termo, ampliando-o, assim, para a valorização das diversas formas representativas culturalmente do que são "identidade cultural, social, racial, de gênero" ${ }^{\prime 2}$, voltando a discussão para uma perspectiva que vai ao encontro do primeiro aspecto destacado pelos Multiletramentos, ligado à diversidade cultural e linguística das sociedades. DW perguntou, então, quais seriam as identidades de cada aluno ali presente e se haveria palavras que representassem a vida deles. Com essas indagações, propôs a temática "Identidade e Palavra" para ser desenvolvida pelos alunos naquele primeiro dia de oficina.

Observa-se que nesse encontro pôs-se em palavras uma das questões estruturantes dos saraus das periferias: a identidade (TENNINA, 2017, p.33). Nos saraus das periferias, existe um fluir constante de corpos, vozes, poemas e performances pautado pelo questionamento sobre identidade e território. A identidade nos saraus, como explica o próprio Eduardo DW, não é tomada como algo unificado e estável, ela é processada por variados posicionamentos de sujeito que vão além da classe social. No mesmo sentido, Homi Bhabha define a noção de identidade no mundo moderno:

O distanciamento das singularidades de "classe" ou "gênero" como categorias conceituais e organizacionais primárias deu como resultado uma consciência das posições de sujeito (posições de raça, gênero, geração, situação institucional, localização geopolítica, orientação sexual) que habitam toda reivindicação de identidade no mundo moderno. (BHABHA, 1994, p.18) ${ }^{3}$.

2. Todos os registros citados são transcrições das gravações de áudio registradas durante a oficina do Projeto Coletivoz "Oficinas de Sarau" em 2017

3. Tradução dos autores. 
Enquanto nos saraus essas linhas temáticas não estão previamente marcadas, nas oficinas elas são explicitadas, aproximando-se de práticas de letramentos escolares pela presença da discussão de um tema definido pelo professor. No entanto, essa característica comum ao gênero discursivo aula, esse falar sobre, aparece nas oficinas em interação com a prática, tanto do oficineiro, que apresenta seus poemas, quanto dos alunos, que são convidados a passar de ouvintes/leitores para poetas/escritores. Sendo assim, trata-se de um convite para a apropriação do que é apresentado, no sentido de tornar próprio, incorporar e transformar, um dos aspectos destacados por Paulino e Cosson (2009) ao caracterizarem o letramento literário. Podemos observar ainda que essa atividade tem como foco a questão da afirmação das identidades como uma prática de reexistência em função de desafiar os preconceitos e discriminações para o "reconhecimento de si" (SOUZA, 2011, p. 37).

Partindo para a prática, depois da explicação sobre identidade, Eduardo DW declamou o seu poema-cançãorap "Com que Roupa", que costuma apresentar nos saraus e slams da cidade. Trata-se da terceira faixa do disco do Projeto Manobra lançado por ele em 2017, em parceria com outros músicos e cantores. Na oficina, sua canção-rap foi modificada, ganhando outra entonação vocal, foi fragmentada, uma vez que ele não declamou o poema completo, e foi analisada com uma leitura reflexiva sobre o conteúdo dos versos e sua forma de construção. Assim sendo, é evidenciado que existem diferenças entre as formas poéticas apresentadas e as demais construções textuais, o que vem ao encontro do terceiro aspecto destacado por Paulino e Cosson sobre o letramento literário: trata-se "da apropriação da literatura", textos que proporcionam uma "forma singular - literária - de construção de sentidos." (PAULINO e COSSON, 2009, p. 68). E a construção de sentidos, nesse caso, envolve o conceito de identidade, a qual não é só abstrata, mas passa em grande medida pelo corpo. A parte declamada por ele foi a seguinte:

Eu vou de ouro, eu vou de cobre, vou de sentimento nobre / Eu vou vestido com as roupas e as armas de Jorge / Com a farda de Fidel,
com os óculos de Cartola / De aba reta, calça larga e tênis bola / E com a camisa do meu time e o ideal de Luther King / Com orgulho
no peito pra dizer "I have a dream" / Vou de verde-amarelo com a cor da pátria amada / Como Ed-Mun, parceiro pro Rap só de toalha
/ Eu vou me vestir com a resistência de Zumbi / Os dreads de Bob Marley e as luvas de Mohamed Ali / Com vulgo e codinome, com
tudo no meu nome / Eu vou de rastafári black e, nos punhos, o microfone / Se vista de style se tua atitude some / Já vi homem fazer
roupa e nunca roupa fazer homem / Eu vou com os beats, eu vou com a Corte e seu convite / Vou construir com Deus e desconstruir
com_Nietzsche / Eu vou de luta de rua, da maioria justa / Mas nunca irei vestido de verdade absoluta / Vou de moda de viola bater um
dedo de prosa / Vou cantando a vida e é o amor que canto agora / Se Noel vai de rosa, a pergunta não se cala: / Com que roupa tu vai
quando for sair de casa? ${ }^{4}$

No poema, a superposição de personagens revolucionários com os seus nomes, suas roupas, penteados e atitudes coloca em primeiro plano a consonância do corpo com a palavra. E não somente do corpo, mas do corpo em movimento, "eu vou", um corpo que avança e se posiciona publicamente ("fora de casa") sem uma verdade absoluta, mas com um sonho claro ("I have a dream"). Esse corpo se associa à identidade como corpo vivente com direito à expressão. De fato, antes dessa declamação, Eduardo DW faz o seguinte comentário aos estudantes: "toda pessoa aqui é importante (...) é uma vida que está aí e ela tem o mesmo direito de expressão de todos". Nas entrelinhas, podemos fazer a seguinte leitura: todo texto escrito nesta oficina e toda leitura feita são importantes. E todo texto feito na oficina traz consigo a própria trajetória do autor que pode, inclusive, já ter produzido poemas e raps. Essa consideração pelo que vem do outro é fundamental, segundo Paulino e Cosson, para o estabelecimento de uma comunidade de leitores na escola, pois "assegura a participação ativa do aluno na vida literária e, por meio dela, a sua condição de sujeito." (PAULINO e COSSON, 2009, p. 74).

Nesse poema, também é possível perceber outra dimensão do conceito de identidade que estrutura os saraus: a de identidade ligada à autoestima. Como é referenciado por Lucía Tennina:

Uma ideia central que estrutura as produções dos saraus vincula-se com a noção de literatura entendida como um território de culto à autoestima dos habitantes da periferia. Tanto a produção poética de muitos frequentadores como suas declarações durante os saraus insistem na concepção da literatura ligada ao culto das capacidades e motivações individuais censuradas geralmente pela ideia de carência que costuma ser associada às condições de vida nos bairros mais pobres e estigmatizados da cidade. (2017, p. 51-52)

As marcas que na sociedade seriam estigmatizantes, nos saraus capitalizam-se simbolicamente. Esse aspecto é evidente no poema de Fellipe Beluca que segue à declamação de Eduardo DW, intitulado "Vambora":

Acorda... Acorda...

Acorda, vambora, a vida já começou...

E começou faz tempo fi.

4. Como as falas dos participantes da oficina, as referências dos poemas citados ao longo deste artigo correspondem ao registro de campo. 
Eu, tô só agregando valores. E no jardim do meu viver, tô regando os meus amores.

Clichê! Se eu parar pra falar sobre o que sinto, já que, quem liga nunca tá por perto. Mas a ponte, é indestrutível e a morada do sossego é meu recinto, e eu permaneço aqui, de braços e peito aberto.

Eu não falo de amor, por ser pra mim uma doutrina, um estado de espírito e mais do que ciência a ser exercida. Sinta, permita-se transmitir, observar, absorver, não abster ao discernir... Sobre o viver, sobreviver não é vivenciar, é encenar e não sentir. Eu prezo por sorriso nos rostos, já atravessei um mar de lágrimas. As páginas foram borradas, apagadas... Um basta nas lástimas!

Vi na minha mãe, o que havia de mais próximo da imagem paterna. Grande mulher, me dá amor e benção, pra eu seguir com minhas próprias pernas.

Me abriram portas, pulei janelas, cortei vielas e esquivei das barcas. Já fechei portas, assoprei 29 velas e o bico deu guela: - "da $15^{\circ}$, esse num passa"...

E eu avancei, mas tô só passando, não a passeio se é que você me compreende. Tô indo na contramão dos que vem na minha direção, e se vende. Se rende nas falhas, não aprende e não cresce com o próprio erro. Se perde nas malhas, finas ou não, se prende ao ego e vai a esmo.

Hoje, a cada instante que corro, se não saio morto, considero mais um dia vencido... Que a mim, fora concebido, mas pra que eu faça valer, e sem atrito. Abro meu livro da vida, era um segredo diário, mas leia quem quiser. Caí na subida, mas de cabeça erguida, sem medo do otário que brinca com a fé...

- Sem ginga, mané, num vinga. Gritar vitória e brindar com as taças vazias. Mas e agora, José?! Mandinga! Essas pinga, já destruíram quantas famílias?! Hein?! Quantas mais, já que um sonho se esvai, prum outro nascer feliz. E como nossos pais, nossa árvore crava cada vez mais, a sua raiz. Ame! ${ }^{5}$

Essa "biografia de lágrimas", ao se transformar em poema, vira um "livro de vida", considerando todas as dores pelas quais o poeta passou e evidencia o processo de "agregar valores" à vida (e não à "sobrevida").

A declamação nos saraus, a escrita e a declamação de poemas na oficina, assim como o próprio ato de realizar a oficina, funcionam como atos de letramentos de reexistência, no sentido atribuído por Ana Lúcia Silva Souza às práticas do mundo dos rappers:

Letramentos de reexistência aqui será a reinvenção de práticas que os ativistas realizam, reportando-se às matrizes e aos rastros de uma história ainda pouco contada, nos quais os usos da linguagem comportam uma história de disputa pela educação escolarizada ou não. (SOUZA, 2011, p. 37).

O processo de refletir sobre identidade que está sendo montado nessa primeira parte da oficina aponta justamente para o trabalho do reconbecimento de si dos alunos, a partir do desafio de deslocar sua atuação de ouvintes e reprodutores dos conhecimentos da escola a falantes e produtores de um conhecimento próprio.

Os poetas-oficineiros conseguiram trabalhar, em diálogo com os estudantes, com teorias complexas e contemporâneas sobre a noção de identidade e a prática dos saraus das periferias. Efetivamente, as oficinas, utilizadas na educação, vêm sendo caracterizadas como importante metodologia pedagógica, centrada na produção coletiva de conhecimento e nas trocas de experiências, o que pressupõe uma "horizontalidade na construção do saber inacabado", conforme definição do Glossário do Centro de Referências em Educação Integral, que destaca ainda sua "dinâmica democrática, participativa e reflexiva que toma como fundamento do processo pedagógico a relação teoria-prática, sem enaltecer a figura do educador como única detentora dos conhecimentos." Para Paviani e Fontana, são "uma forma de construir conhecimento, com ênfase na ação (...) numa oficina ocorrem apropriação, construção e produção de conhecimentos teóricos e práticos, de forma ativa e reflexiva." (PAVIANI e FONTANA, 2009, p. 78).

Paralelamente à teorização sobre identidade, nesse primeiro dia da oficina, apresenta-se uma teorização sobre o que é um sarau da periferia, como forma de evidenciar que por trás dessas manifestações não existem habilidades inatas dos poetas-oficineiros, mas sim um processo de socialização na sua construção.

Em primeiro lugar, os saraus são mostrados como um lugar de pertencimento. Na apresentação do poetaoficineiro Beluca no começo do encontro, sua identidade é caracterizada a partir dos saraus das periferias: "Eu sou do Coletivoz, eu sou do Cabeça Ativa, eu sou de qualquer sarau que tem na cidade, e eu sou do Ipê também que é um grupo de rap daqui da cidade". Ser de um sarau de uma periferia é, de certo modo, ser de todos os saraus das periferias, inclusive da própria Cooperifa de São Paulo, por mais que esteja em outra cidade. Dessa forma, podemos observar a existência de uma grande "comunidade de leitores", formada por todos os saraus, que possui um repertório comum de valores, textos, gostos e formas de se vestir, de falar, de sentir o mundo. Dentro dessa grande comunidade, estão as comunidades de cada cidade e de suas regiões. A formação de uma comunidade de leitores é a primeira prática

5. A disposição gráfica do poema neste artigo foi retirada do livro À Luta. À voz (MACHADO; OLIVEIRA (org.), 2018), "uma coletânea escrita por vinte e dois poetas da cena da literatura marginal e periférica de Belo Horizonte e região metropolitana que passaram e passam pelo Sarau Coletivoz" (Disponível em: https://www.venasabiertas.com.br/portfolio_item/a-luta-a-voz-edicao-especial/). Na declamação feita na oficina, o poeta manteve-se fiel ao texto publicado. 
apontada por Paulino e Cosson (2009) para ajudar a concretizar o letramento literário na escola, fazendo com que a escola imite a vida, ou seja, trabalhe com as práticas que circulam em nossa sociedade.

Os saraus são apresentados também como "um espaço de expressão" para "discutir a nossa identidade". Observa-se que essa ideia de expressão está constantemente associada à ideia de "liberdade", liberdade de tomar a palavra, liberdade de não tomar a palavra, liberdade de escolher estar ou não estar na oficina. Essas "liberdades" remetem a comportamentos que costumam ser repreendidos no espaço escolar. Aqui a palavra (e o silêncio) motivamse a partir não de regras fixas, mas de afecções no sentido spinoziano de "efeito instantâneo de uma imagem/coisa" (DELEUZE, 2003, p.79) que leva a um outro estado. E essa transição, neste caso, tem a ver com estabelecer um relacionamento com a palavra vinculado ao reconhecimento de si.

Esse processo de construção de conhecimento está marcado constantemente a partir de uma palavra ligada às diversas ações que constituem a oficina: "provocação". Durante a oficina essa palavra é repetida incansavelmente, mas não no sentido que poderia ser associado ao senso comum, isto é, provocar uma briga, e sim no sentido de afetar uma pessoa de forma a potencializar positivamente os seus estímulos. O ponto é que não se trata de pensar no sujeito a partir da ideia de melhorá-lo, o que levaria ao horizonte de uma identidade fechada e fixa, mas no campo da relação, ou seja, pensar o sujeito em relação com algum outro elemento ou sujeito que o afeta positivamente.

Depois das declamações dos poeta-oficineiros, Eduardo DW propôs que cada estudante escrevesse um poema ou uma canção rap, em diálogo com o tema identidade, para depois declamá-los, evidenciando a "sobreposição e interação" (STREET, 2014) que existe nesse processo de letramento entre a oralidade e a escrita. Essa atividade, em que a escrita é utilizada na interação com a literatura, é destacada por Paulino e Cosson (2009) como a quarta prática que contribui para a concretização do letramento literário na escola. Segundo os pesquisadores, o objetivo não é formar escritores, mas "oferecer aos alunos a oportunidade de se exercitarem com as palavras, apropriando-se de mecanismos de expressão e estratégias de construção de sentidos que são essenciais ao domínio da linguagem e da escrita." (PAULINO e COSSON, 2009, p. 76). Observa-se que a escrita literária não faz parte dos objetivos escolares, que almejam formar exclusivamente leitores. Mesmo na proposta de Paulino e Cosson, a escrita é colocada como uma espécie de exercício para a apropriação da linguagem verbal.

Para a produção escrita proposta na oficina, os poetas-oficineiros levaram os estudantes para outro espaço físico, a biblioteca do centro cultural, sentando-se no chão, ou seja, estabelecendo com esse espaço regrado um vínculo outro a partir do não respeito das regras do silêncio e do uso das cadeiras. Formaram-se dois grupos: um, guiado pelo DW, trabalhou a partir do verso gatilho "eu vou" e o outro, acompanhado pelo Beluca, a partir do eu sou. Essas duas formas de mobilizar a palavra dos estudantes também foram chamadas de "provocação" e, para estimular a escrita, a produção foi acompanhada pelo som de suaves músicas instrumentais.

Após esse momento, DW levou os estudantes novamente para o auditório e propôs uma dinâmica de apresentação dos poemas feitos por cada um, instigando os alunos a construírem um "sarauzinho" de encerramento daquele $1^{\circ}$ dia de oficina. Antes do início desse ensaio de sarau, para provocar as apresentações, o poeta-oficineiro fez uma pergunta que ligava o mundo dos saraus ao da escola: "qual é a importância disso na formação de vocês?". Em seguida realizou uma reflexão de que a oficina poderia ampliar as possibilidades de criação da escrita em processos seletivos como o Exame Nacional do Ensino Médio (ENEM). Eduardo DW sustentou essa reflexão sobre a potência da escrita criativa com base em sua experiência pessoal, por já ter vivenciado o processo de preparação para esse exame considerado, em suas palavras, "muito difícil para quem mora nas periferias". Parte-se do pressuposto de que a escrita em si, independentemente do gênero, já se configura como uma prática importante, que pode facilitar a produção dos demais gêneros escritos, como a dissertação do ENEM. Podemos observar, por outro lado, que o exemplo do exame não é colocado como uma forma de estimular uma educação escolarizada, pelo contrário, o que é valorizado é a escrita criativa dos saraus e das oficinas, concebidos como espaços de apropriação de ferramentas para conquistar direitos.

Em seguida, o poeta-oficineiro deslocou-se para o terreno do gozo dizendo que ver aquele processo de esforço da criação escrita já era bonito por si só, uma vez que os próprios alunos refletiam sobre suas vidas e, consequentemente, sobre suas diversas identidades. O poeta, então, entrou em ação recitando a segunda parte daquele poema-canção que tinha apresentado na abertura como forma de provocar a sensibilidade criativa dos estudantes para o exercício em grupo. Depois dessa intervenção, iniciou-se o sarauzinho, e quem puxou o bonde foi a professora da escola, que declamou o seguinte: 
Eu sou o não sei e sei que preciso saber

saber de tudo é um desejo, mas quem é que tudo sabe?

eu sou o querer estar só e amar estar com alguém

a solidão é um privilégio, ter amigos também

Eu sou o que o tempo fez comigo e o desejo do que está por vir

eu sou o que o presente precisa desde que eu possa transformá-lo

eu sou o desejo de mudança e o amor de tudo que ficou como está

o que eu sou só diz respeito a mim desde que o mundo possa usufruir

Essa declamação funcionou também como uma provocação, uma vez que a professora, que como tal ocupa o lugar do saber aos olhos dos estudantes, construiu o seu poema a partir do verso "eu sou o não sei e sei que preciso saber", definindo-se, então, a partir da falta de saber. Depois das palmas, tomou a palavra um aluno partindo da premissa "eu vou":

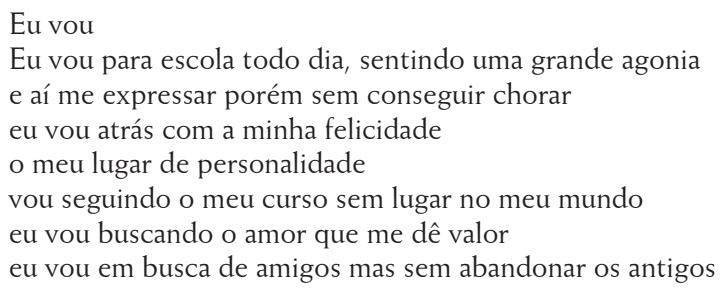

Diferentemente do eu sou, que leva os poemas a uma dimensão mais abstrata e a temáticas universais como o amor, o saber, o tempo, o eu vou apresenta um cotidiano povoado de pessoas, de ruas, de detalhes que fazem com que o poema alcance uma dimensão mais íntima em certos momentos.

No sarauzinho, os poemas foram lidos pelos próprios autores, porém um deles pediu a Eduardo DW para que ele lesse o seu poema. Depois de um tempo curto da apresentação pelo oficineiro, o aluno pediu a palavra e finalizou a leitura, assumindo o papel de leitor de sua própria criação poética. Esse reposicionamento de aluno/autor-ouvinte para aluno/ autor-falante de seu texto autoral simbolizou uma provocação coletiva para os demais alunos que seguiram entrando com mais ânimo no jogo do sarau naquele final da primeira manhã da oficina. Esse acontecimento levou ainda a uma reflexão teórica ligada à outra dimensão da identidade que é a própria voz, como destacou o poetaoficineiro Beluca: "este ato de ler é importante para marcar a expressão da voz do autor", pois "a gente tá no processo de construir a identidade". Não somente o conteúdo do que é lido constitui identidade, mas também o jeito de falar, veio a dizer o oficineiro.

Durante as apresentações, o tempo do sarau foi limitado pelos tempos institucionais, pois a professora interveio falando que alguns alunos deviam partir por terem outras atividades na escola. Do mesmo modo que, durante um sarau em um bar, o tempo necessário para o descanso da comunidade limita o horário do encontro, aqui também ocorre um cruzamento de tempos que põe um limite no fluir de corpos, vozes e aplausos. Mas, paradoxalmente, quando o tempo começou a acabar, o ritmo do sarau mudou, desaparecendo os comentários entre os poemas apresentados e ficando só as palmas. Os poemas começaram a ser declamados um atrás do outro, como um dominó, fazendo com que o objetivo da oficina fosse cumprido: os alunos, agora poetas, tomaram a palavra, apropriando-se de práticas de letramento literário e integrando-se a uma comunidade de leitores.

Quando o sarau finalizou, quem tomou a palavra foi a professora da turma, posicionando-se mais uma vez distante das práticas escolares e evidenciando que encontrou um campo de letramento muito rico na prática do sarau:

Nós temos uma atividade que fazemos na escola (...) e aí tá rolando um problema porque o outro professor já está fazendo e eu tô achando que a gente não precisa usar nenhuma literatura externa porque tá tudo aqui, tudo que a gente precisa está aqui na produção de texto de vocês, eu acho que a gente pode fazer baseado naquilo que vocês fizeram.

Podemos observar, na fala da professora, um distanciamento em relação a uma certa concepção de literatura e uma legitimação das produções dos alunos. Com isso, há um questionamento do cânone escolar e uma crítica ao modus operandi da escola tradicional, que, em geral, "enfatiza demasiadamente o conhecido e o mensurável, negando espaço para o estranho e o inusitado." (PAULINO e COSSON, 2009, p. 71).

Esse uso dos textos literários produzidos pelos próprios alunos contribui para uma das práticas, mencionadas por Paulino e Cosson, de concretização do letramento literário na escola, que consiste em "ampliar e consolidar 
a relação do aluno com a literatura" (2009, p. 75), o que implica que "o aluno compreenda que a literatura se faz presente em sua comunidade não apenas nos textos escritos e reconhecidos como literários..." (2009, p. 75).

Podemos notar que um repertório comum está sendo construído para além do espaço escolar, fundamental para a formação de uma comunidade de leitores. Dentro de uma concepção de leitura como prática social, o leitor é considerado enquanto membro de uma comunidade que partilha determinados códigos de interpretação de textos, aprendidos na própria comunidade. Esse aspecto é destacado por Stanley Fish (1980) ao definir sua concepção de comunidade interpretativa como "uma entidade pública e coletiva composta por todos aqueles que partilham uma mesma estratégia de interpretação, um mesmo modelo de produção de textos ou que contam a mesma história acerca do mundo" (apud DIONÍSIO, 2000, p. 92). Essa comunidade é formada aqui pelos poetas-oficineiros, pelos alunos e pela professora.

Podemos observar que as práticas de letramento presentes nessa oficina provocaram uma desestabilização de discursos cristalizados da escola,

Os letramentos de reexistência mostram-se singulares, pois, ao capturarem a complexidade social e histórica que envolve as práticas cotidianas de uso da linguagem, contribuem para a desestabilização do que pode ser considerado como discursos já cristalizados em que as práticas validadas sociais de uso da língua são apenas as ensinadas e aprendidas na escola formal. (SOUZA, 2011, p. 36).

A escola, depois da oficina de sarau, será vivenciada de uma outra forma pelos estudantes do $3^{\circ}$ ano do Ensino Médio e pela professora da turma. O encontro foi finalizado, então, com mais risos do que silêncio e com o convite para dar "umas palmas para todo mundo".

\section{CONSIDERAÇÕES FINAIS}

Neste artigo, a partir da descrição das falas e ações dos participantes no primeiro dia da oficina de sarau realizada pelo Coletivoz Sarau de Periferia em uma escola municipal da região do Barreiro, em Belo Horizonte, identificamos e analisamos eventos e práticas de letramento literário, buscando aproximações, diálogos e rupturas com as práticas presentes na escola.

Observamos que os eventos e as práticas de letramento da oficina são marcados pela interação das fórmulas rituais dos saraus das periferias com as da escola, incorporadas nos participantes e recriadas nesse encontro fora dos bares e da instituição escolar. Contudo, a disposição dos corpos no espaço, o uso que fazem do ambiente da biblioteca, as temáticas abordadas e o próprio uso da escrita, enquanto direito de tomarem a voz e se apresentarem como poetas, fazem emergir práticas de letramento que se distanciam das comumente encontradas nas escolas.

O questionamento identitário presente nas discussões, a organização da oficina (metodologia e fórmulas rituais) e as ações dos participantes integram o que estamos denominando de práticas de letramentos literários de reexistências. Observa-se, assim, que, para caracterizar essas práticas, o letramento literário deve ser pensado no plural e, aproximando-se de um dos aspectos dos multiletramentos, liga-se à diversidade cultural e linguística das sociedades. Destaca-se que a apropriação/incorporação e a transformação/leitura da literatura não são habilidades, mas são processos que implicam exercícios de conhecimento e reconhecimento de práticas sociais de comunidades de leitores, que vão além dos muros escolares.

$\mathrm{Na}$ interação entre escola e sarau periférico, por meio das oficinas, abre-se, para os poetas-oficineiros, uma instância de teorização e reflexão sobre a própria prática. Cria-se a possibilidade de a escola revisitar suas práticas de letramento, ampliando seu repertório, revendo suas metodologias e também contribuindo com práticas de letramentos literários de reexistências. Finalmente, essa dinâmica sarau-escola leva os estudantes a um exercício inédito: estabelecer um relacionamento com a palavra vinculado ao reconhecimento de si.

\section{REFERÊNCIAS}

BHABHA, Homi (1994). El lugar de la cultura. Buenos Aires: Manantial.

CAZDEN, Courtney. et al. (1996). A Pedagogy of Multiliteracies: Designing Social Futures. Harvard Educational Review, v. 66, n.1, p. 60-92, Spring Disponível em: http://newarcproject.pbworks.com/f/Pedagogy+of+Multiliteracies_ New+London+Group.pdf. Acesso em: 14 jul. 2021. 
COELHO, Rogério Meira. (2017). A palavração: atos político-performáticos no Coletivoz Sarau de Periferia e Poetry Slam Clube da Luta. Dissertação de Mestrado em Artes da Cena. Escola de Belas Artes, UFMG, Belo Horizonte.

COELHO, Rogério Meira. (2015). Projeto Coletivoz Oficinas de Saraus. Fundação Municipal de Cultura. Edital Descentra Cultura.

DELEUZE, Gilles. (1970). Trad. Equipo Editorial Cactus. En medio de Spinoza. Buenos Aires: Cactus, 2003.

DIONÍSIO, Ma.Lou.A. (2000). A construção escolar de comunidades de leitores. Leituras do livro de Português. Coimbra: Almedina.

FÉLIX, Camila. (2018). Atlas dos Saraus: mapeamento dos saraus de poesia da região metropolitana de Belo Horizonte. Monografia em Arquitetura e Urbanismo. Faculdade de Arquitetura e Urbanismo, UFMG, Belo Horizonte.

MACHADO, Dione; OlIVEIRA, Karine (org.). À luta, à voz. Coletivoz Sarau de Periferia - Coletânea Poética. Belo Horizonte: Venas Abiertas, 2018.

NASCIMENTO, Érica Peçanha do (2006). Literatura marginal: os escritores da periferia entram em cena. Dissertação de Mestrado em Antropologia Social. Faculdade de Filosofia, Letras e Ciências Humanas, Universidade de São Paulo, São Paulo.

NASCIMENTO, Érica Peçanha do. (2011). É tudo nosso! Produção cultural na periferia paulistana. Tese de Doutorado em Antropologia Social. Faculdade de Filosofia, Letras e Ciências Humanas, Universidade de São Paulo, São Paulo.

OFICINAS (2021). In: CENTRO DE REFERÊNCIAS EM EDUCAÇÃO INTEGRAL. Glossário. Disponível em: http:// educacaointegral.org.br/glossario/oficinas/. Acesso em: 12 jul.jul. 2021.

PAULINO, Graça. (1998). Letramento literário: cânones estéticos e cânones escolares. Caxambu: ANPED. (Anais em CD $\mathrm{ROM}$ )

PAULINO, Graça e COSSON, Rildo. (2009). Letramento literário: para viver a literatura dentro e fora da escola. In: ZILBERMAN, Regina e RÖSING, Tania M.K. (Orgs.) Escola e leitura: velha crise. Novas alternativas. São Paulo: Global.

PAVIANI, Neires Maria Soldatelli e FONTANA, Niura Maria. (2009). Oficinas pedagógicas: relatos de uma experiência. Conjectura, Caxias do Sul, v. 14, n. 2, p. 77-88.

REYES, Alejandro (2013). Vozes nos porões. A literatura periférica/marginal do Brasil. Rio de Janeiro: Aeroplano.

SOUZA, Ana Lúcia Silva. (2011). Letramentos de reexistência: poesia, grafite, música, dança: hip-hop. São Paulo: Parábola Editorial.

STREET, Brian e CASTANHEIRA, Maria Lúcia. (2014). Glossário Ceale. In: Glossário Ceale: termos de alfabetização, leitura e escrita para educadores. Isabel Cristina Alves da Silva Frade, Maria da Graça Costa Val, Maria das Graças de Castro Bregunci (orgs). Belo Horizonte: UFMG/Faculdade de Educação. Disponível em: http://www.ceale.fae.ufmg.br/app/ webroot/glossarioceale/verbetes/praticas-e-eventos-de-letramento. Acesso em: 12 jul.2021.

STREET, Brian (1996). Letramentos Sociais: abordagens críticas do letramento no desenvolvimento, na etnografia e na educação. São Paulo: Parábola Editorial, 2014.

TENNINA, Lucía (2017). Cuidado com os poetas! Literatura e periferia na cidade de São Paulo. Porto Alegre: ZOUK.

Recebido: 31/7/2021

Aceito: 14/10/2021

Publicado: 26/10/2021 